\title{
Comparison of Speculum and Non-speculum Vaginal Specimens in the Diagnosis of Trichomonas vaginalis
}

\author{
Obunge Orikomaba Korifama ${ }^{1}$, Oboro Ibinabo Laura ${ }^{1}$, Onyejepu Nneka ${ }^{2}$, \\ Alex-Wele Mary Adanma ${ }^{1}$ \\ ${ }^{1}$ Department of Medical Microbiology, University of Port Harcourt Teaching Hospital, Port Harcourt, Nigeria \\ ${ }^{2}$ Centre for Tuberculosis Research, Nigeria Institute of Medical Research, Lagos, Nigeria
}

Email address:

ibinabo.oboro@gmail.com (Oboro I. L.)

\begin{abstract}
To cite this article:
Obunge Orikomaba Korifama, Oboro Ibinabo Laura, Onyejepu Nneka, Alex-Wele Mary Adanma. Comparison of Speculum and Nonspeculum Vaginal Specimens in the Diagnosis of Trichomonas vaginalis. International Journal of Infectious Diseases and Therapy. Vol. 5, No. 2, 2020, pp. 41-44. doi: 10.11648/j.ijidt.20200502.14
\end{abstract}

Received: May 22, 2020; Accepted: June 9, 2020; Published: June 20, 2020

\begin{abstract}
Trichomoniasis is the most prevalent non-viral sexually transmitted infection worldwide. Apart from being a key biologic indicator of sexual activity, it's been associated with the transmission of Human Immunodeficiency virus. The use of vaginal speculum is traditionally required for specimen collection. The limited application of this step in various primary health care facilities in resource-poor settings due to difficulties with sterilization of speculae among others, has grossly reduced the offer of testing for Trichomoniasis. Self-collected vaginal swab could be an acceptable alternative specimen for diagnosis of trichomoniasis in these settings. We compared the yield of Trichomonas vaginalis from speculum and nonspeculum based specimens. Five hundred women between $18-45$ years presenting with abnormal vaginal discharge in two health care facilities in Rivers State, Nigeria, were enrolled. Three specimens were collected from each woman; two nonspeculum based /non-invasive and the third, speculum based. Microscopists were trained and the procedure standardized. Wet mount microscopy was performed on all specimens within thirty minutes of collection. Three Microscopists examined each specimen independently. All infected patients were managed according to existing guidelines. Ethical approval was obtained and data analyzed using SPSS version 21. Median age of participants was 31 years. Of the 500 women, 53 were infected giving an overall prevalence of $10.6 \%$. Using the speculum-based specimens, $90.5 \%$ (48) of infected women were detected while $83.0 \%$ (44) and $30.1 \%$ (16) were detected using the self-collected swab and first void urine respectively. Interestingly, first void urine was able to detect five (5) more cases that were not detected by the speculum-based method. In low income settings, use of self-collected swabs in combination with first void urine is likely to increase detection rate of Trichomonas vaginalis when compared with the use of speculum-based specimen only.
\end{abstract}

Keywords: Trichomoniasis, Speculum, Diagnosis, Trichomonas vaginalis

\section{Introduction}

Trichomonas vaginalis (T. vaginalis) infection is the most prevalent non-viral sexually transmitted infection worldwide [1]. Estimated global incidence was about 156 million cases in 2016 [2]. In Nigeria prevalence varies across regions [3-8]. T. vaginalis has been recognized as a key biologic indicator of sexual activity as it is transmitted quite directly, primarily by sexual intercourse from human to human, being its only known host [9]. It has also been shown to be a risk factor for acquisition /infection and transmission of the Human
Immunodeficiency Virus (HIV) [10-12]. In Nigeria where HIV infection remains a public health burden [13, 14] it is essential to optimize efforts to control risk factors associated with the transmission of this infection.

Several studies have also shown that pregnant women infected with Trichomonas vaginalis are at increased risk of adverse birth outcomes such as pre term delivery and low birth weight babies $[15,16]$. This high index of neonatal mortality has to be addressed using all available preventive approach. It is desirable that health care facilities are in a position to promptly diagnose and treat this curable protozoan infection and in this way reduce the perinatal 
impact of the infection as well.

Culture is considered the gold standard for its diagnosis $[17,18]$. It is generally accepted in developing countries that the diagnosis of trichomoniasis can be based on microscopic visualization of the motile trichomonads. Acceptability of this approach is due to the low technical demand, rapidity, achievable cost and acceptable sensitivity and specificity of the process [19]. This can be achieved through direct saline wet mount of vaginal secretion. Some authors argue that in few instances, the absence of trichomonads in saline mount microscopy can be a false negative result and may require further processing with a nucleic acid amplification technique, the Polymerase Chain Reaction [18, 20].

Speculum insertion into the vagina is traditionally a required step for specimen collection. The limited application of this step in various primary health care facilities has grossly reduced the offer of testing for $T$. vaginalis. The reasons for this limitation include; technical difficulties associated with sterilization of the speculum, correct use of speculum by health care workers, perceived pain reported by clients and cultural inhibitions as well as religious inclinations in the African setting. In some settings adolescent clients totally refused speculum insertion [21].

The use of urine as an alternative non-invasive specimen is being practiced in some settings, however; it has been documented that with this, the sensitivity of the wet microscopy as a diagnostic technique is significantly reduced $[17,18]$. We propose that self-collected vaginal swab, a situation where patients collect their own specimens, could be an acceptable alternative sample for the diagnosis of trichomoniasis in patients who report copious abnormal vaginal discharge. This procedure is already acceptable for techniques that require DNA amplification for diagnosis of other sexually transmitted diseases such as genital chlamydia and gonorrhea [22].

In this study we compared the yield of $T$. vaginalis from wet preparation using various specimen collection techniques namely; High vaginal swab (HVS), self-collected vaginal swab and first void urine (FVU) from a female population in a resource limited setting.

\section{Method}

Five hundred women aged between 18-45 years presenting with abnormal vaginal discharge in two healthcare facilities in Rivers State were enrolled into the study. Three specimens were collected from each woman; a Physician collected High vaginal swab, self-collected Swab and first void urine. To do this, Women were required to insert a sterile swab stick deep (about $3 \mathrm{~cm}$ ) into their vagina and keeping a hold on the handle of the stick, rotate clock wise and then anticlockwise and re-insert into the tube then subsequently provide 20 -
$30 \mathrm{mls}$ of first void urine in a sterile pre-labeled container. High vaginal swab (HVS) was thereafter taken in the course of pelvic examination by a Clinician. Vaginal Swabs were transported to the bacteriology bench of the laboratory immediately, placed in a test tube containing a few drops of sterile normal saline solution and wet mounts of the fluid examined microscopically for motile Trichomonads.

Urine specimens were transported to the urine bench of the laboratory, centrifuged at 2000rpm for 5 minutes, supernatant discarded and the sediment re-suspended in the drop of supernatant remaining in the tube. This was examined under the microscope.

Microscopists were trained and procedures standardized. Wet mount was carried out for all specimens within 30 minutes of collection. Each Microscopist attached to a specimen was blind to the result of the other specimen types. A Positive Trichomonad result was only recorded once for each patient irrespective of the mode of collection of the specimen. All patients with infection were managed according to existing guidelines. Ethical approval and informed consent was obtained for this study. Data was analyzed using SPSS Version 21.

\section{Results}

The study participants' ages ranged from 18-45 years with a median age of 31 years. A total of 53 out of the 500 women investigated, were infected giving an overall prevalence of $10.6 \%$ (Figure 1).

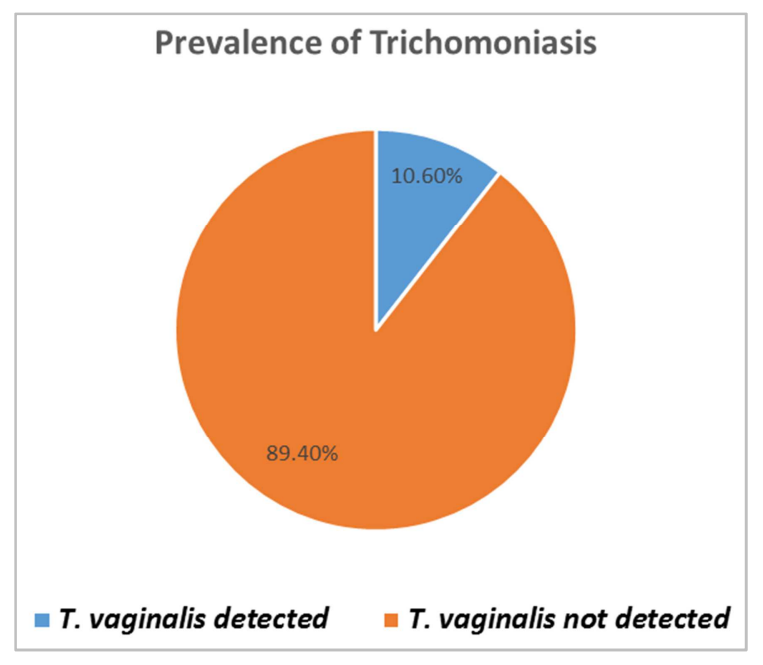

Figure 1. Prevalence of T. vaginalis.

From the speculum-based High vaginal swab, 90.5\% $(48 / 53)$ of infected women were detected while $83.0 \%$ $(44 / 53)$ and $30.1 \%(16 / 53)$ were detected using the selfcollected swab and first void urine respectively (Table 1).

Table 1. Comparison of specimen collection methods in detecting Trichomonas vaginalis.

\begin{tabular}{lllll}
\hline \multirow{2}{*}{ Method of collection } & \multirow{2}{*}{ Speculum Based } & Non Speculum Based & & \\
\cline { 3 - 5 } & & Urine & Self-Collected (SC) & Urine plus SC \\
\hline Number Detected N (\%) & $48(90.5 \%)$ & $16(30.1 \%)$ & $44(83.0 \%)$ & $49(92.4 \%)$ \\
\hline
\end{tabular}


Four (4) of the infections which were diagnosed from the speculum-based specimens were missed using the selfcollected swab, however; using the first void urine specimen, we detected 5 more infected women that were missed using the speculum-based specimen. These were probably women who had predominantly urethritis and so were missed by a carefully collected high vaginal swab using a speculum. On combination of self-collected swabs and first void urine for diagnosis, we were able to detect 49 out of $53(92.4 \%)$ infected women.

\section{Discussion}

Many studies have shown that the prevalence of Trichomonas infection is highest among women 40 to 49 years old [23]. This is slightly higher than was observed in our study even though both age groups fall within the sexually active age group. Prevalence rates of trichomoniasis ranging from less than $1 \%$ to about $51.8 \%$ have been reported across Nigeria [24] some being much less and others quite similar to that in our study. In other parts of Africa and globally, prevalence rates ranging from $1.7 \%$ to even as high as $54 \%$ have been reported $[22,25,26]$.

Self-collection of vaginal swab for diagnosis of sexually transmitted diseases is being advocated globally especially when pelvic examination will not add value to the management of the patient [27]. In Nigeria, Halpern et al. [13] opted for self-collected swabs to assay for gonoccoal and chlamydial infections using genotypic techniques.

In an earlier study, Brabin et al. [3] showed that in southern Nigeria, the prevalence of sexually transmitted diseases was higher in the 17-19 years age group when compared to the higher age groups and this group of teenagers tend not to accept invasive vaginal procedures. Smith et al. [28] assessed the acceptability of self-collection of vaginal swabs amongst an adolescent population; all their clients opted for this approach. Holland-Hall et al. [21] also argued that the lack of the self-collection option could lead to missing over $70 \%$ of sexually transmitted diseases amongst adolescent girls in a juvenile facility.

Forney et al. [29] validated the use of self-collected swabs for longitudinal study of the vaginal flora.

Also important to note is that there was no difference in the vaginal microbiota when comparing self-collected and physician-collected vaginal swabs from these women. The primary focus on self-collected swabs had been to utilize this approach for procedures with amplification steps, however; our result shows that this innovative approach can also be validated for conventional diagnostic procedures in management of sexually transmitted diseases.

First void urine has also been shown to be of added value in diagnosis of trichomoniasis [20] as females may also have urethritis in addition to vaginitis. The usefulness of first void urine also applies to male partners who are infected with Trichomonas vaginalis. The combination of self-collected swabs and first void urine was noted to have a higher detection rate as it was able to detect $92.4 \%$ of infections, which is more than detected from either method alone. This is very exciting as we believe, it will enable healthcare facilities equipped for microscopy but who lack technical expertise and other requirements to sustain aseptic speculum use, to carry out etiologic diagnosis of trichomoniasis. This is similar to reports and recommendations by Ogale et al. [30] and Shafer et al. [22] among others.

Other studies have shown a similar pattern to our findings with reports of comparable sensitivity, specificity and predictive values between self-collected and physician (speculum-based) collected swabs [31,32] for diagnosis of $T$. vaginalis using various diagnostic methods.

\section{Conclusion}

We are of the opinion that self-collected swabs will contribute significantly in assisting health care providers practicing in resource poor settings to reduce missed cases in management of sexually transmitted diseases. The use of self-collected vaginal swabs in combination with first void urine is likely to increase the detection rate of Trichomonas vaginalis in low income settings, when compared with the use of speculum-based specimen only.

\section{References}

[1] Menezes CB, Frasson AP, Tasca T. Trichomoniasis - are we giving the deserved attention to the most common non-viral sexually transmitted disease worldwide?. Microb Cell. 2016; 3 (9): 404-419. doi: 10.15698/mic2016.09.526.

[2] Rowley J, Vander Hoorn S, Korenromp E, Low N, Unemo M, AbuRaddad L et al. Chlamydia, gonorrhoea, trichomoniasis and syphilis: global prevalence and incidence estimates, 2016. Bull World Health Organ. 2019; 97: 548-562P| doi: http://dx.doi.org/10.2471/BLT.18.228486.

[3] Brabin L, Kemp J, Obunge OK, Ikimalo J, Dollimore N, Odu $\mathrm{NN}$ et al. Reproductive tract infections and abortion among adolescent girls in rural Nigeria. Lancet. 1995; 345: 300-304.

[4] Ijasan O, Okunade KS, Oluwole AA. The prevalence and risk factors for Trichomonas vaginalis infection amongst human immunodeficiency virus-infected pregnant women attending the antenatal clinics of a university teaching hospital in Lagos, SouthWestern, Nigeria. Niger Postgrad Med J. 2018; 25 (1): 21-26.

[5] Obunge OK, Brabin L, Dollimore N, Kemp J, IkokwuWonodi C, Babatunde S et al. A flowchart for managing sexually transmitted infections among Nigerian adolescent females. Bull World Health Organ. 2001; 79 (4): 301-5.

[6] Oladeinde BH, Oladeinde OB, Imade OS, Onifade AA. Trichomonas vaginalis infection among women of reproductive age in a rural community in Nigeria. Niger J Exp Clin Biosci 2016; 4: 1-5.

[7] Akinbo FO, Mokobia CN, Ande AB. Prevalence of trichomoniasis among pregnant women in Benin City. Sahel Med J 2017; 20: 67-71.

[8] Feldblum PJ, Lie CC, Weaver MA, Van Damme L, Halpern V, Adeiga A et al. Baseline factors associated with incident HIV and STI in four microbicide trials. Sex Transm Dis. 2010; 37 (10): 594-601. 
[9] Kissinger P. Epidemiology and Treatment of Trichomoniasis. Curr Infect Dis Rep. 2015 June; 17 (6): 484. doi: 10.1007/s11908-015-0484-7.

[10] Mavedzenge SN, Pol BV, Cheng H, Montgomery ET, Blanchard K, de Bruyn G et al. Epidemiological synergy of Trichomonas vaginalis and HIV in Zimbabwean and South African women. Sex Transm Dis. 2010 Jul; 37 (7): 460-6.

[11] Halpern V, Obunge O, Ogunsola F, Otusanya S, Umo-Otong J, Wang $\mathrm{C}$ et al. Interim data monitoring to enroll higher-risk participants in HIV prevention trials. BMC Medical Research Methodology. 2009; 9: 44. doi: 10.1186/1471-2288-9-44.

[12] Naidoo S, Wand H, Abbai NS, Ramjee G. High prevalence and incidence of sexually transmitted infections among women living in Kwazulu-Natal, South Africa. AIDS Res Ther. 2014; 11: 31. https://doi.org/10.1186/1742-6405-11-31.

[13] Halpern V, Ogunsola F, Obunge O, Wang C, Onyejepu N, Oduyebo $\mathrm{O}$ et al. Effectiveness of Cellulose Sulfate Vaginal Gel for the Prevention of HIV Infection: Results of a Phase III Trial in Nigeria. PLoS ONE 2008, 3: e3784.

[14] UNAIDS, Nigeria. Available at https://www.unaids.org/en/regionscountries/countries/nigeria. Accessed April 17th, 2020.

[15] Kamal AM, Ahmed AK, Mowafy NME, Shawki HE, Sanad AS, Hassan EE. Incidence of Antenatal Trichomoniasis and Evaluation of Its Role as a Cause of Preterm Birth in Pregnant Women Referring to Minia University Hospital, Egypt. Iran J Parasitol: Vol. 13, No. 1, Jan-Mar 2018, pp. 58-66.

[16] Coleman JS, Gaydos CA, Witter F. Trichomonas vaginalis Vaginitis in Obstetrics and Gynecology Practice: New Concepts and Controversies. Obstet Gynecol Surv. 2013 January; 68 (1): 43-50. doi: 10.1097/OGX.0b013e318279fb7d.

[17] Richardson E, Sellors JW, Mackinnon S, Woodcox V, Howard M, Jang D et al. Prevalence of Chlamydia trachomatis infections and specimen collection preference among women, using self-collected vaginal swabs in community settings. Sex Transm Dis. 2003; 30: 880-5.

[18] Adjei C, Boateng R, Dompreh A, Okyere B, Owiredu EW. Prevalence and the evaluation of culture, wet mount, and ELISA methods for the diagnosis of Trichomonas vaginalis infection among Ghanaian women using urine and vaginal specimens. Trop Med Health. 2019; 47: 33. doi: 10.1186/s41182-019-0162-9.

[19] Fule S R, Fule R P, Tankhiwale N S. Clinical and laboratory evidence of Trichomonas vaginalis infection among women of reproductive age in rural area. Indian J Med Microbiol 2012; 30: 314-6.

[20] Asmah RH, Agyeman RO, Obeng-Nkrumah N, Blankson H, Awuah-Mensah G, Cham M et al. Trichomonas vaginalis infection and the diagnostic significance of detection tests among Ghanaian outpatients. BMC Women's Health. 2018; 18: 206. https://doi.org/10.1186/s12905-018-0699-5.

[21] Holland-Hall CM, Wiesenfeld HC, Murray PJ. Self-collected vaginal swabs for the detection of multiple sexually transmitted infections in adolescent girls. J Pediatr Adolesc Gynecol. 2002 Dec; 15 (5): 307-13.

[22] Shafer MA, Moncada J, Boyer CB, Betsinger K, Flinn SD, Schachter J. Comparing first-void urine specimens, selfcollected vaginal swabs, and endocervical specimens to detect Chlamydia trachomatis and Neisseria gonorrhoeae by a nucleic acid amplification test. J Clin Microbiol. 2003; 41: 4395-4399.

[23] Van Der Pol B. Clinical and Laboratory Testing for Trichomonas vaginalis Infection. Journal of Clinical Microbiology. Dec 2015, 54 (1) 7-12; DOI: 10.1128/JCM.02025-1.

[24] Omorodion Oriri Asemota Trichomoniasis in Nigeria: a review. Biomedical Research 2018; 29 (12): 2532-2539.

[25] Centres for Disease Control and Prevention. Trichomoniasis. Available at https://www.cdc.gov/std/trichomonas/stats.htm. Accessed June 7, 2020.

[26] Darvin Scott Smith. Trichomoniasis. Available at https://emedicine.medscape.com/article/230617-overview\#a6. Accessed 10th may, 2020.

[27] Association of Public Health Laboratories. Advances in Laboratory Detection of Trichomonas Vaginalis (Updated). Infectious Diseases. NOVEMBER 2016 Available at https://www.aphl.org/aboutAPHL/publications/Documents/ID 2016November-Laboratory-Detection-of-Trichomonasupdate.pdf. Accessed April 21, 2020.

[28] Smith K, Harrington K, Wingood G, Kim Oh M, Hook EW, DiClemente RJ. Self-obtained Vaginal Swabs for Diagnosis of Treatable Sexually Transmitted Diseases in Adolescent Girls. Arch Pediatr Adolesc Med. 2001; 155: 676-679.

[29] Forney LJ, Gajer P, Williams CJ, Schneider GM, Koenig SS, McCulle SL et al. Comparison of self-collected and physiciancollected vaginal swabs for microbiome analysis $\mathrm{J}$ Clin Microbiol. 2010; 48 (5): 1741-8.

[30] Ogale Y, Yeh PT, Kennedy CE, Toskin I, Narasimhan M. Self-collection of samples as an additional approach to deliver testing services for sexually transmitted infections: a systematic review and meta-analysis. BMJ Global Health. 2019; 4 (2): e001349. DOI: 10.1136/bmjgh-2018-001349.

[31] Khan Z, Bhargava A, Mittal P, Bharti R, Puri P, Khunger N, Bala M. Evaluation of reliability of self-collected vaginal swabs over physician-collected samples for diagnosis of bacterial vaginosis, candidiasis and trichomoniasis, in a resource-limited setting: a cross-sectional study in India. BMJ Open. 2019 Aug 27; 9 (8): e025013. doi: 10.1136/bmjopen2018-025013. PMID: 31462459; PMCID: PMC6719764.

[32] Van Der Pol B, Williams JA, Taylor SN, Cammarata CL, Rivers CA, Body BA, Nye M, Fuller D, Schwebke JR, Barnes M, Gaydos CA. Detection of Trichomonas vaginalis DNA by Use of Self-Obtained Vaginal Swabs with the BD ProbeTec Qx Assay on the BD Viper System Journal of Clinical Microbiology. Feb 2014, 52 (3) 885-889; DOI: 10.1128/JCM.02966-13. 